\title{
Saber hacer y tradición en La Chamba, Colombia: un estudio etnográfico de la selección de arcillas
}

Savoir-faire et tradition à La Chamba (Colombie) : étude ethnographique du choix des argiles

Savoir faire and tradition in La Chamba, Colombia: an ethnographic study of the selection of clays

\section{Angela María Cadena Muñoz}

\section{(2) OpenEdition}

\section{Journals}

Edición electrónica

URL: https://journals.openedition.org/bifea/11504

DOI: 10.4000/bifea.11504

ISSN: 2076-5827

\section{Editor}

Institut Français d'Études Andines

\section{Edición impresa}

Fecha de publicación: 1 abril 2020

Paginación: 19-40

ISSN: 0303-7495

\section{Referencia electrónica}

Angela María Cadena Muñoz, «Saber hacer y tradición en La Chamba, Colombia: un estudio etnográfico de la selección de arcillas», Bulletin de l'Institut français d'études andines [En línea], 49 (1)। 2020, Publicado el 08 agosto 2020, consultado el 24 agosto 2021. URL: http:// journals.openedition.org/bifea/11504 ; DOI: https://doi.org/10.4000/bifea.11504

\section{(c) $(1) \odot$}

Les contenus du Bulletin de l'Institut français d'études andines sont mis à disposition selon les termes de la licence Creative Commons Attribution - Pas d'Utilisation Commerciale - Pas de Modification 4.0 International. 


\title{
Saber hacer y tradición en La Chamba, Colombia: un estudio etnográfico de la selección de arcillas
}

\author{
Angela María Cadena Muñoz
}

\begin{abstract}
Resumen
La selección de materias primas para la elaboración de artefactos cerámicos es relevante para comprender la relación entre alfareros/as y arcilla a través de sus representaciones sociales y para evitar sesgos interpretativos en los análisis arqueológicos sobre los factores que influyen en la decisión de su adquisición. A través de un estudio etnográfico que involucra un análisis de las narrativas y la cultura material, se describen las decisiones técnicas tomadas por cinco alfareros/as de La Chamba (suroccidente de Colombia) para la extracción de arcilla. Este estudio muestra que, más que por factores ambientales, las decisiones de la selección de la materia prima están mediadas por el saber hacer y la tradición.
\end{abstract}

Palabras clave: La Chamba, cerámica, selección de arcilla, tecnología

\section{Savoir-faire et tradition à La Chamba (Colombie) : étude ethnographique du choix des argiles}

\section{Résumé}

Le choix des matières premières pour la fabrication d'objets en céramique est pertinent afin de comprendre la relation entre potiers et argile par le biais des représentations sociales, et afin d'éviter les biais interprétatifs des analyses archéologiques concernant les facteurs qui influencent les choix d'acquisition de l'argile. Par le biais d'une étude ethnographique impliquant une analyse des discours et de la culture matérielle, nous décrivons les choix techniques opérés par cinq potiers et potières de La Chamba (sud-ouest colombien) pour extraire l'argile. Cette étude montre que le savoir-faire et la tradition jouent un rôle plus important dans le choix des matières premières que les facteurs environnementaux.

Mots-clés : La Chamba, céramique, sélection d'argile, technologie

*Antropóloga/docente, Universidad de Caldas, Colombia. E-mail: angela.cadena@ucaldas.edu.co. 


\title{
Savoir faire and tradition in La Chamba, Colombia: an ethnographic study of the selection of clays
}

\begin{abstract}
The selection of raw materials for the elaboration of ceramic artifacts is relevant to understand the relationship between potters and clay through their social representations and to avoid interpretative biases in archaeological analyses of the factors that influence the decision of potters in the acquisition of clay. Through an ethnographic study involving an analysis of narratives and material culture, the technical decisions for clay extraction made by five potters from La Chamba (Southwestern Colombia) are described. This study shows that rather than environmental factors, raw material, selection decisions are mediated by savoir faire and tradition.
\end{abstract}

Keywords: La Chamba, ceramics, clay selection, technology

\section{INTRODUCCIÓN}

La tecnología es una producción social que abarca las elecciones arbitrarias de técnicas, acciones físicas, materiales y demás, que son componentes integrales de un sistema simbólico mayor que define la manera en que los individuos perciben y modelan el mundo (Lemonnier, 1992: 2). Es precisamente, bajo esta premisa, que se propone el análisis de los componentes que definen la tradición cerámica de la comunidad de La Chamba (Guamo-Tolima), acentuando las acciones técnicas relacionadas con la selección de la materia prima, puesto que esta corresponde a la primera fase de la cadena operativa de fabricación. Este análisis pertenece a un avance investigativo que se ha realizado con la intención de efectuar aportes a la interpretación arqueológica de la producción cerámica a partir de la constatación etnográfica, teniendo en cuenta el sesgo interpretativo que han tenido algunos estudios cerámicos en Colombia. Estos últimos han producido, principalmente, tipologías morfoestilísticas y descripciones de piezas que pormenorizan la complejidad y variabilidad de las relaciones entre los materiales y los seres humanos.

La Chamba es una vereda (mínima división territorial de Colombia) del municipio de El Guamo, en el departamento del Tolima (centro-oeste de Colombia) (fig. 1). El área municipal es de $523 \mathrm{~km}^{2}$. Limita por el norte con el municipio El Espinal; por el este, con los municipios de Suárez y Purificación; por el sur, con Saldaña; y, por el oeste, con San Luis. Su altitud es cercana a los 320 m s. n. m., lo que hace que tenga un piso térmico templado, una temperatura promedio de $34^{\circ} \mathrm{C}$ y un sistema biótico natural con formación de bosque seco tropical (Bs-T) (Corporación Autónoma Regional del Tolima [Cortolima], 2009: 16). 


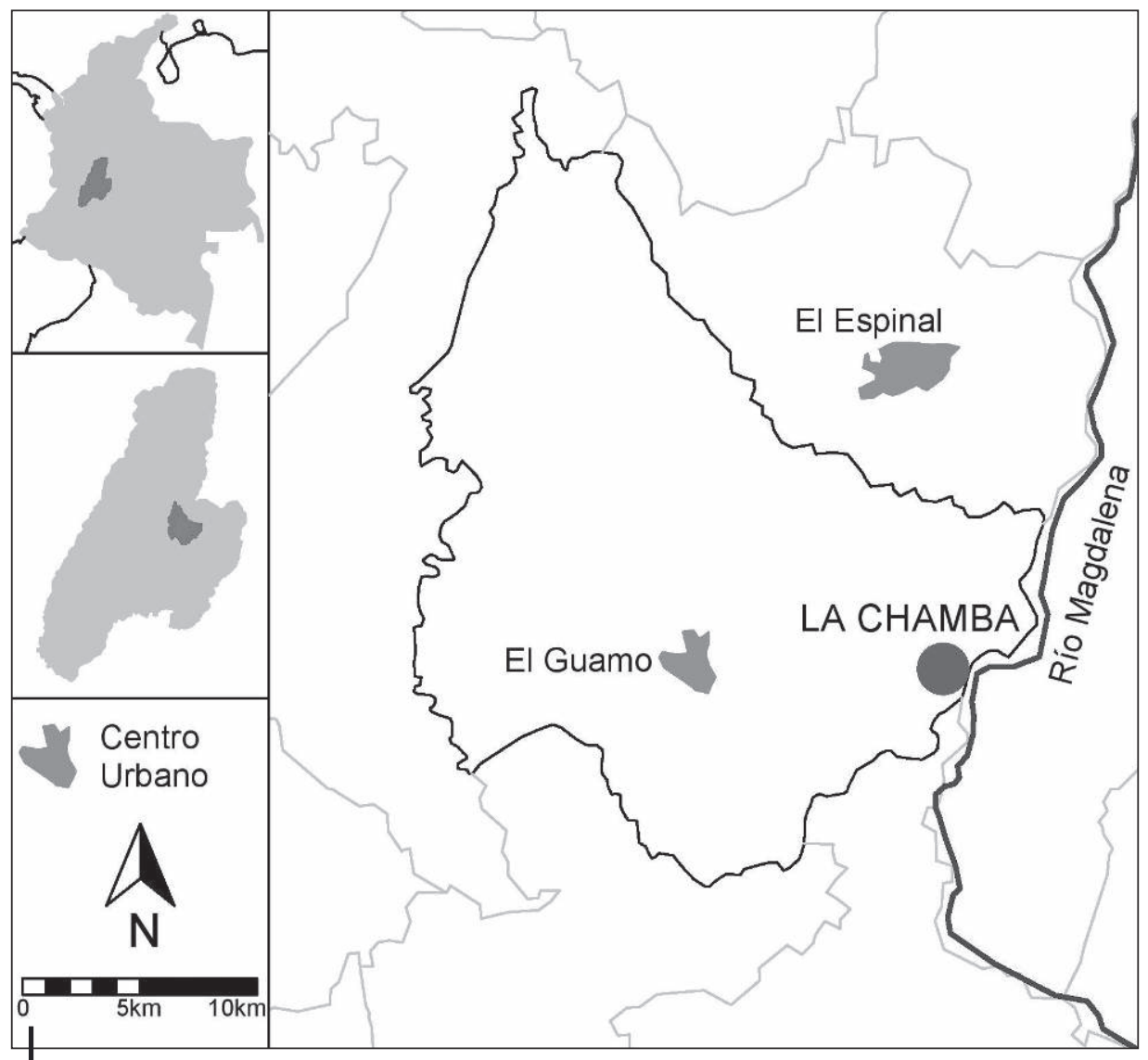

Figura 1 - Mapa de ubicación geográfica de La Chamba

Fuente: Elaboración propia

El río Magdalena recorre el valle aluvial que define la zona; por lo tanto, esta se caracteriza por un paisaje plano con segmentos ondulados. Geológicamente, el valle está formado por los yacimientos de arcillas usados por alfareros/as, que contienen abundantes elementos volcánicos generados por las formaciones Gualanday, Honda y Mesa; existen también arcillas residuales provenientes de cuerpos ígneos intrusivos y extrusivos. Este material arcilloso fue trasladado aluvialmente hasta el valle y es característico de la baja planicie del Tolima en los abanicos de El Espinal, donde predominan materiales volcánicos procedentes de erupciones de la Cordillera Central (Cifuentes Toro, 1994; Pulido González, 2019).

La Chamba es considerada como uno de los principales centros alfareros del país. Allí habitan alrededor de 339 familias, de las cuales más del 85 \% participa directamente en el proceso de manufactura de artefactos cerámicos domésticos y utilitarios, siendo el trabajo artesanal su principal sustento económico (Ministerio de Cultura, 2014: 2). 
Los implementos que se fabrican, como platos, ollas, múcuras (recipientes de boca angosta y cuerpo globular que sirven para almacenar y transportar líquidos), bandejas, pocillos, entre otros, conservan técnicas de elaboración tradicionales que la comunidad asocia a los grupos prehispánicos que se asentaron allí, pues en este territorio se hallaron distintos objetos de cerámica que permiten pensar en un quehacer ancestral.

La secuencia de ocupaciones prehispánicas en el valle del Magdalena tolimense está conformada por dos periodos, el Temprano y el Tardío. En el Periodo Temprano se evidencian dos complejos cerámicos, Montalvo (1000 a. C.-1 a. C.) y Guamo Ondulado (1 a. C.-700 d. C.) (Salgado López et al., 2007). Al primero se le asignan características como finas copas, botellones, vasijas globulares (en ocasiones con soportes), cuencos y platos con decoración esgrafiada y pintura negra aplicada (en diversos diseños geométricos) sobre baños y engobes rojos, cafés de diferentes tonalidades y negros (Salgado López et al., 2007). Al segundo, se le relaciona con cuencos de boca ancha, de borde reforzado y decorados con impresiones dactilares, vasijas subglobulares de borde reforzado con acanaladuras, cuencos y copas (Cifuentes Toro, 1996: 23).

El complejo Magdalena Inciso es característico del Periodo Tardío. Según los datos registrados por Salgado López et al. (2007), tienen una temporalidad que se extiende desde el primer milenio a. C. hasta los siglos XVI-XVII de nuestra era. Sus materiales se caracterizan por la presencia de vasijas sencillas de mediano y gran tamaño, acompañadas por otras que pueden hacer las veces de tapas. También son comunes los recipientes globulares con asas, cuencos, platos, figurinas sólidas y volantes de huso con motivos incisos; la decoración más frecuente es la incisión en diversos diseños geométricos, el pastillaje con diferentes trazos incisos presionados, muescas y baños de tonalidades rojas y cafés. Este complejo tiene como expresión más representativa el horizonte de urnas de la cuenca del río Magdalena, también Ilamado «horizonte cerámico del Magdalena Medio» (Salgado López et al., 2007: 271).

Al respecto, Cifuentes Toro (1994: 24) indica que la cerámica de La Chamba tiene cerca de 400 años de antigüedad (ca. 1620 d. C. 330+/-60 ap. Beta 92198). En conjunto con el análisis de datos etnohistóricos, sugiere que grupos étnicos prehispánicos, como los pijao y coyaimas, elaboraron piezas cerámicas con superficies rojas, cafés y negras, las cuales denominó tipológicamente como Chamba Baño Rojo Pulido (dentro de esta cabe el subgrupo Chamba Negro Pulido) y Chamba Café Presionado.

El tipo Chamba Baño Rojo Pulido se asemeja a los materiales elaborados en la actualidad por la comunidad de La Chamba, puesto que los fragmentos hallados en contextos arqueológicos tienen baño rojo y el acabado de ambas superficies es pulido; además, las formas se asocian a cuencos (10-12 cm de diámetro), ollas globulares, tinajas (8-26 cm de diámetro) y cazuelas.

El subgrupo Chamba Negro Pulido se encuentra asociado a la cerámica Baño Rojo Pulido, pues cuenta con el mismo tipo de baño y acabado de las superficies. Sin embargo, su color negro supone un procesamiento diferente que se puede asociar 
al proceso de reducción intencional (ahumado) aún utilizado por la comunidad (Cifuentes Toro, 1994: 15). Este procedimiento consiste en depositar las piezas rojas en recipientes metálicos o cerámicos (moyas) para su cocción. Después de asadas, aún calientes, se añade bosta a los objetos y se tapa durante aproximadamente quince minutos. En este proceso, la circulación del aire se reduce y el hidrógeno y carbono presentes en la atmósfera transforman el color rojo en negro.

El tipo Chamba Café Presionado está formado por vasijas globulares, subglobulares y cuencos, con diámetros entre 6 y $24 \mathrm{~cm}$, además de bases de copas, múcuras y platos. Las decoraciones corresponden a presionados triangulados que se localizan sobre el hombro de las piezas y el labio; algunas presentan también incisiones en el cuello y la mitad del cuerpo (Cifuentes Toro, 1994: 16).

En la actualidad, los objetos cerámicos son elaborados con técnicas tradicionales. El modelado por rollos es característico, así como el uso de moldes para definir las bases. Cuando la forma de la pieza está establecida, se agrega engobe rojo a las superficies, para luego hacerlas brillar. La cocción, en la mayoría de los casos, se realiza en hornos tipo iglú, hechos con arcilla y guadua. Estos incluyen recipientes metálicos (canecas) para disponer los objetos y también ahumarlos, y así generar el color negro característico de las piezas cerámicas que realiza esta población.

Artesanos/as catalogan los artefactos según sus características físicas (color y brillo) y por su dedicación en la manufactura, clasificándolos como cerámica negra (brillante), de combate (recipientes de elaboración rápida con poco detalle, cuidado y escaso brillo) y roja. Las formas más comunes de estos elementos son cazuelas, platos, ajiceras, ollas y pocillos que tienen como fin el uso doméstico y utilitario (fig. 2).

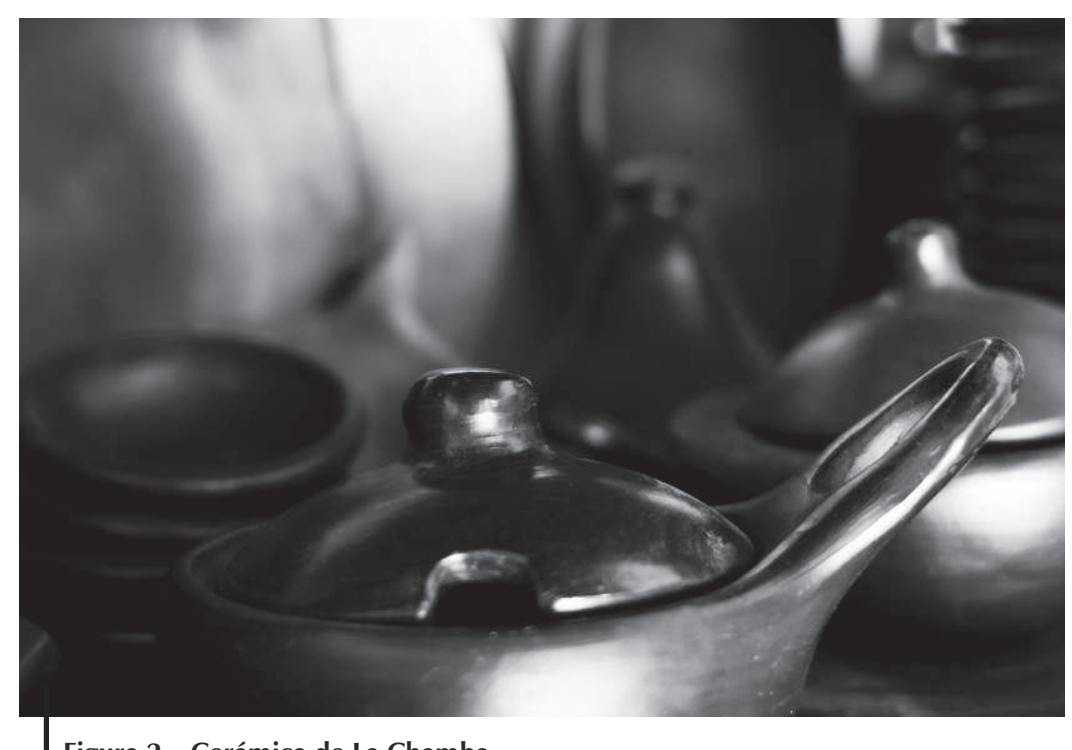

Figura 2 - Cerámica de La Chamba

(c) Andrés Uribe Naranjo 
Ahora bien, esta comunidad ha dado forma a una serie de estrategias que conforman su organización tecnológica, debido a lo cual las técnicas cerámicas y los procesos manuales de elaboración, como son la manufactura, el engobe y el bruñido, son realizadas en primacía por las mujeres; los hombres aportan con su trabajo en labores asociadas a la captación de arcilla y la quema y reducción de las piezas.

En este sentido, es importante comprender que un proceso tecnológico no solo da cuenta de una secuencia de acciones o de pasos a seguir para moldear un artefacto, sino que también evidencia esquemas sociales que se han establecido y arraigado a través del tiempo, por medio de la enseñanza y el saber hacer compartido generacionalmente. Estos gestan el conocimiento técnico del grupo y forjan una tradición (Calvo Trías \& García Roselló, 2014: 8).

\section{ANTECEDENTES TEÓRICOS}

La perspectiva etnoarqueológica ha estado sujeta a muchas críticas en las que se ha cuestionado no solo la utilidad de sus ideas en la práctica contemporánea, sino también la ética del investigador (Lyons \& Casey, 2016). Recientemente, Oliver Gosselain (2016) ha expuesto una fuerte crítica a este método, en la que, nuevamente, trae a colación la discusión centrada en el uso de las analogías, exhibiendo la circularidad inmersa en ellas a causa de la creencia de la continuidad histórica entre los contextos prehistóricos, históricos y etnográficos. Adicionalmente, considera que no hay discusión sobre las prácticas de campo ni comentarios sobre la recopilación de datos o la naturaleza de los datos recopilados. Gosselain también resalta que el fin de la etnoarqueología se deriva de cuestiones teóricas y conceptuales generadas fuera de esa subdisciplina; en ese sentido, propone que se realice una reformulación completa de los objetivos, los métodos y la filosofía de la misma.

Por su parte, investigadores como Politis (2002; 2014; 2015), Lyons \& Casey (2016) y González-Ruibal (2017) destacan la relevancia de la etnoarqueología, justificando que tales críticas provienen de la falta de precisión en torno al concepto de analogía. De esta manera, exponen que la etnoarqueología ya no consiste en estudios breves de estrategias de subsistencia, sino en estudios a largo plazo que buscan específicamente comprender lo material dentro de lo social (Lyons \& Casey, 2016: 612). Asimismo, indican que es esencial que la etnoarqueología sea reconocida como un método, ya que proporciona fuentes de información que ayudan a los arqueólogos a pensar en las relaciones humano-materiales fuera de su propia experiencia y a evaluar teorías en contextos de la vida real (Lyons \& Casey, 2016: 622).

La posición de este estudio asume los puntos de vista de investigadores como Politis, Lyon \& Casey y González-Ruibal, en el sentido en que los resultados etnoarqueológicos no pretenden ser fórmulas para interpretar el registro arqueológico, sino que, a través del análisis etnográfico, se propone información 
y se generan interrogantes con el fin de dar forma al análisis y a las preguntas arqueológicas. En consecuencia, García Roselló (2008: 20) indica que el objetivo de la disciplina es la correspondencia entre las sociedades vivas y la cultura material, con la intención de conocer las relaciones de esta con otros aspectos de la cultura y la sociedad.

El análisis tecnológico demuestra la existencia de una infinidad de maneras de resolver los mismos problemas técnicos y gran cantidad de prácticas diferentes se utilizan para alcanzar los mismos objetivos. La suma de estas decisiones es compartida y transmitida por el grupo a través del saber hacer (Pelegrin, 1985 citado en Vidal \& García Roselló, 2010). A estas se les puede ver como estrategias de producción, es decir, como la posibilidad de seleccionar una o varias acciones técnicas entre muchas más elecciones a utilizar (opción tecnológica). Por lo tanto, se considera que la tradición alfarera se halla inmersa entre la materialidad dispuesta en las cadenas de producción, las acciones tecnológicas y el saber hacer que pueden llegar a constituir la memoria de una comunidad (fig. 3). Así, es posible definir la manera en que los agentes, consciente e inconscientemente, tomarán decisiones limitadas en torno a las posibilidades relacionadas con la manufactura de un producto, puesto que dicha información se encuentra ligada a tradiciones que han sido incorporadas en un sentido práctico.

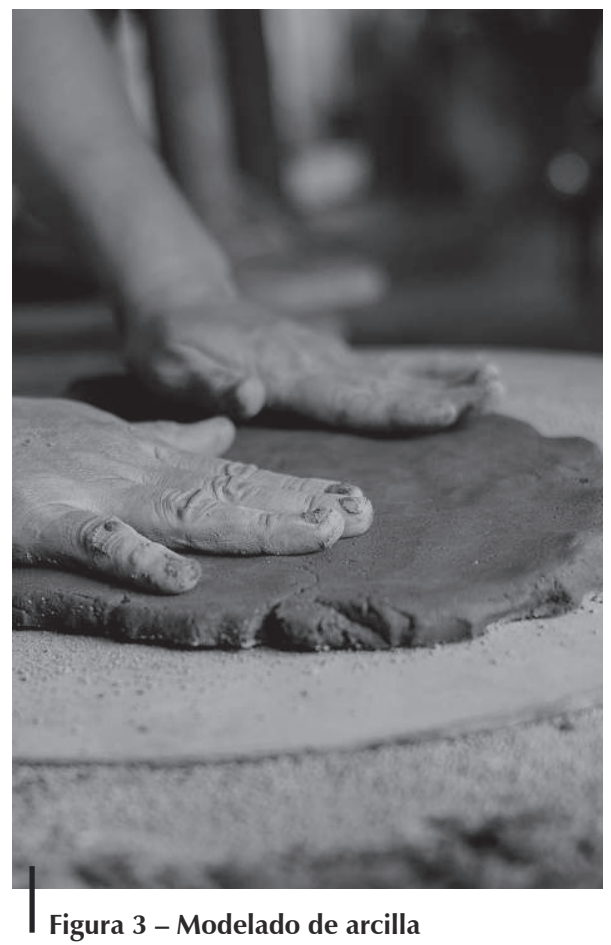

(C) Andrés Uribe Naranjo

En el estudio realizado por Gosselain \& Livingstone Smith (2005) en el área del subSahara en África, se encuentran ejemplos de ello, en donde los investigadores dan cuenta de la complejidad y la variabilidad de los comportamientos relacionados con la selección y el procesamiento de la arcilla. Estos exploran los mecanismos subyacentes a las variaciones espaciales y temporales de las tradiciones asociadas con esta acción técnica e infiriendo que las elecciones específicas de los/as alfareros/as corresponden a una combinación inextricable de hábitos heredados, limitaciones técnicas y funcionales, representaciones personales, herramientas y posturas utilizadas en otras actividades y recetas simbólicas.

En el área andina, Druc (2009) realiza una investigación sobre las tradiciones contemporáneas del distrito de Conchucos, ubicado al norte del departamento de Áncash (margen oriental de la cordillera Blanca, noroccidente de Perú). Definió 
dos tradiciones alfareras, una femenina, que utiliza el enrollado como única técnica de elaboración en la parte sur de Conchucos (Huari), y otra masculina, caracterizada por el uso del paleteado como técnica secundaria de elaboración, en el centro de Conchucos (cuenca sur del río Yanamayo). Las tradiciones cerámicas en cada zona muestran diferencias importantes en su tecnología y manera de producción, sugiriendo una evolución cerámica distinta dentro de comunidades diferentes, pero que se hallan en contextos espaciales cercanos.

Ramón Joffré (2011) brinda otros datos relevantes al respecto cuando expone los resultados de trabajos etnoarqueológicos con alfareros rurales de los Andes peruanos (alfareros golondrinos), quienes dejan sus comunidades domésticas para elaborar piezas cerámicas en otros lugares, es decir, que tienen migraciones relacionadas con el ciclo agrícola, desplazándose a otras aldeas en donde elaboran productos de acuerdo a las preferencias del cliente y/o disposición de materiales en cada lugar. De esta forma, los alfareros itinerantes dejan su huella tecnológica; así, tipos de materias primas, formas, decoraciones, entre otras, marcarán las decisiones de producción de una comunidad.

En Colombia, Daniela Castellanos ha centrado su interés en la comunidad alfarera de Aguabuena, en Ráquira-Boyacá, con la intención de definir un marco simbólico e ideológico que determina las relaciones entre la cultura material y la gente.

Indica que en los talleres es posible identificar los procesos naturales de formación del registro arqueológico y procesos culturales relacionados con el complejo ciclo de vida que cumple la cultura material antes de ser descartada, los cuales determinan la visibilidad arqueológica de las distintas actividades involucradas en la producción alfarera. Allí, los objetos, sus significados y sus relaciones participan de imponderables que median tanto su vida social como su registro arqueológico (Castellanos, 2007: 7).

Además, reconoce las pautas de comportamiento de los habitantes de Aguabuena en relación con las vasijas que producen, como es el caso de las manifestaciones de la envidia en el mundo material.

Puesto que la envidia sale del cuerpo, se encarna en el cuerpo, se lanza hacia otro cuerpo que así lo siente y necesita del cuerpo (humanos o no: nótese que las vasijas también tienen una anatomía que implica un cuerpo) (Castellanos, 2019: 54).

También realiza un análisis sobre los fragmentos, en donde indaga, entre otras cosas, sobre la restauración de los caminos.

Uno de los usos más comunes es el empleo de fragmentos de vasijas rotas, o tiestos, como los llaman los alfareros, para rellenar los huecos de la carretera sin pavimentar que cruza el cerro donde se encuentra Aguabuena y que es el principal medio de acceso al lugar. Desde la construcción de esta vía, en la segunda mitad del siglo XX, los alfareros la han mantenido, siendo los fragmentos el hilo conector entre Aguabuena y el mundo (Castellanos, 2012: 244).

Este tipo de investigaciones da cuenta de la relevancia de los datos etnoarqueológicos, pues sugiere otras estrategias de producción cerámica 
que rompen los sesgos interpretativos en arqueología. Es precisamente lo que se procura con este artículo, pues se busca entender la relación que tiene la comunidad de alfareros de La Chamba, Tolima, con la arcilla, aspecto relevante que podría no ser fácil de captar analizando solo la cultura material, y que, además, abre nuevas perspectivas sobre las decisiones de producción inmersas en la elaboración cerámica. Este acercamiento tiene como fin analizar a este grupo alfarero actual a través de la etnografía, con el propósito de aportar información pertinente para la creación de hipótesis y extender el alcance interpretativo de los estudios de material arqueológico.

\section{TRABAJO DE CAMPO}

En La Chamba, la alfarería se aprende con la acción, por consiguiente, participar de las actividades diarias es la vía de acceso para comprender la materialidad, la gestualidad, las normativas y el fluir de los actos asociados a las acciones técnicas y al saber hacer tradicional. Por lo tanto, a través de la participación y la entrevista se busca «comprender los fenómenos sociales desde la perspectiva de sus miembros» (Guber, 2011: 5).

Montero Fayad (2002) realizó su trabajo etnográfico en La Chamba; sin embargo, esta investigadora realizó entrevistas tanto a los alfareros como a las personas que trabajan en artesanías de Colomba S. A., sociedad de economía mixta del orden nacional que tiene como objetivo incrementar la participación de los artesanos en el sector productivo del país. Esto con el fin de observar y analizar los espacios en los que la artesanía circula para definir cómo se construyen significados alrededor de los objetos artesanales, situándolos en relación con los textos que anuncian, difunden y promueven —mitos, revistas de decoración, propaganda, folletos turísticos, entre otros-, en conexión con las prácticas de quienes los producen y los venden, los miran o los compran (Montero Fayad, 2002: 5).

A mediados de la década de los noventa, Arturo Cifuentes ejecutó un trabajo pionero en el sector, esta vez haciendo énfasis en el componente arqueológico. Sin embargo, fue inviable para él proponer un análisis cerámico arqueológico sin comprender las dinámicas alfareras que en su momento se observaban en ese lugar. Realizó un recorrido histórico de la región, una serie de entrevistas informales y registró fotográficamente las actividades relacionadas con las estrategias técnicas.

Con base en estos datos, describe y propone la existencia de una tradición alfarera, puesto que se pueden asociar a los métodos de fabricación del pasado prehispánico: tiras en rollo; pulimento y brillo con piedra; ausencia de torno; selección de arcillas; quema a cielo abierto, así como en horno en forma de colmena, los cuales fueron introducidos por los españoles; secado de la cerámica a la sombra y al sol; fijada del color negro mediante ahumado; y la utilización de cañas para dar contorno a las piezas (Cifuentes Toro, 1994: 64).

Para el caso puntual de esta investigación, la información se obtuvo a partir de cinco visitas entre los años 2016 y 2019 a la vereda, con el fin de entablar 
relaciones y conocer las pautas tecnológicas alfareras. La primera visita se efectuó en la última semana del mes de septiembre del año 2016, con la intención de conocer personalmente el lugar, a los habitantes, crear afinidades y definir sus estrategias productivas. Del 14 al 17 de octubre del mismo año, el encuentro se concibió con la finalidad de asistir al festival del barro y evidenciar las prácticas asociadas a este evento. En 2017 y 2018, las visitas se realizaron, casualmente, en el mes de mayo y en 2019, en junio. Cada uno de estos momentos tuvo una duración de alrededor de dos semanas, en las que, cada vez, los lazos con los/as alfareros/as fueron más cercanos, permitiendo conocer las prácticas y las estrategias de la producción cerámica a través de la entrevista abierta.

Este tipo de entrevista se convierte, a su vez, en una observación que conlleva a la participación de labores cotidianas con el grupo o con los individuos. Por lo tanto, se tomó parte de las actividades alfareras buscando reconocer aspectos relacionados con las estrategias de elección del material arcilloso, tales como sitios de obtención del material (canteras), técnicas para la extracción de la materia prima, características para escoger la arcilla, significado de la materia prima, entre otros.

Si bien sería ideal trabajar con toda la población, el tiempo y el presupuesto limitan esta posibilidad. Por lo tanto, se tomó la decisión de trabajar solo con cinco personas, específicamente, con tres alfareras y dos alfareros, puesto que reúnen características propias para el análisis de esta tradición.

Doña Carmen Prada es nativa de La Chamba y su fábrica lleva su nombre. Su edad le ha permitido perfeccionar técnicas y conservar en su saber hacer pautas que el tiempo ha dejado atrás, como, por ejemplo, la obtención del efecto de brillo con piedras de río o la producción de formas específicas como las múcuras, también la exigencia en el modelado.

Doña Eurimia Avilés (Ilamada «Muñeca»), también oriunda de La Chamba, es una gran representante de las alfareras. Dedica la mayor parte de su tiempo al modelado de las piezas y tiene claro que compartir su conocimiento es esencial para preservar la tradición; disfruta enseñar y le gusta innovar en sus productos.

Don Idelfonso Avilés (también Ilamado «don Pacho»), es el hermano de «Muñeca». Ambos conservan el legado de sus padres, la fábrica de artesanías Don Pacho - La Muñeca. Don Idelfonso fue el primer contacto que se tuvo con La Chamba. «Don Pacho» dedica el tiempo a la extracción de la arcilla, la cocción de las piezas, el procesamiento de la pasta, y promociona los productos y la fábrica por internet.

Doña Yanire Álvarez no es nativa de la vereda; sin embargo, aprendió las técnicas. Las primeras piezas que elaboró fueron platos; de ahí pasó a las cazuelas y ajiceras, que son los productos que más vende junto con su compañero, don Arcesio Prada. Él es originario de La Chamba y colabora en las actividades de producción, tales como el brillado, la obtención de la arcilla, el procesamiento de la pasta y la cocción.

No fue fácil tomar la decisión de seleccionar a los/as alfareros/as, puesto que a medida que más cercanía se tiene con la población, mayores son las relaciones 
que se crean y las opciones de trabajar con cada uno. Sin embargo, al acompañar a estas cinco personas en sus labores, se pudo mantener cierto control en los datos, tanto a nivel social como artefactual, lo cual permitió obtener mayores detalles sobre las características particulares de los/as alfareros/as, y, por ende, enriquecer el análisis de la cadena de producción.

En este sentido, estas personas compartieron su conocimiento, historias y acciones técnicas, tales como extracción, preparación de las pastas, modelado, brillado y cocción. La recopilación de sus historias y saberes permitió la comprensión e interpretación de su tecnología, pues estas dan cuenta de la forma en que el grupo, en general, se representa en relación con la materia prima, las herramientas y los objetos elaborados.

Adicionalmente, las observaciones de campo se han fortalecido con la lectura del paisaje y datos geológicos de la zona. Es relevante establecer la relación con los lugares más adecuados (por ejemplo, proximidad, facilidad de extracción) para la captación de la materia prima y compararlos con las decisiones reales tomadas por los artesanos. La información geológica ha evidenciado importantes diferencias entre los lugares de selección de la materia prima y aquellos que podrían representar menos costos para su obtención.

\section{RESULTADOS}

Los suelos de La Chamba están conformados por arenisca gris-verdosa y limolitas silíceas en una matriz arcillosa que alcanza espesores de $10 \mathrm{~m}$, así como por materiales que se derivan de arcillolitas rojas y grises (Cortolima, 2009: 20), los cuales son particularmente favorables al uso alfarero. En este sentido, es factible que este material pudiera extraerse de cualquier lugar del sector, como los patios traseros de las casas, perfiles de suelo expuestos o minas. Sin embargo, la comunidad ha definido ciertas estrategias para hacerlo.

Dichas estrategias permiten que se establezca la posibilidad de seleccionar una o varias acciones entre muchas más elecciones a utilizar, por lo que la colectividad tiene establecido el uso de tres minas, la de la arcilla lisa o greda, la arcilla arenosa y la arcilla roja, donde obtienen el material que compone la pasta y el engobe.

\section{1. Las minas}

\section{1. 1. Santelmo y Arenosa}

La arcilla lisa o gredosa y la arcilla arenosa que componen la pasta de los artefactos son captadas en minas comunitarias localizadas cada una a una distancia promedio de 1,3 km del casco urbano de La Chamba (véase la fig. 4). La arcilla lisa se halla en la mina Santelmo (véase la fig. 5) y la arenosa, en la mina homónima (véase la fig. 6). 


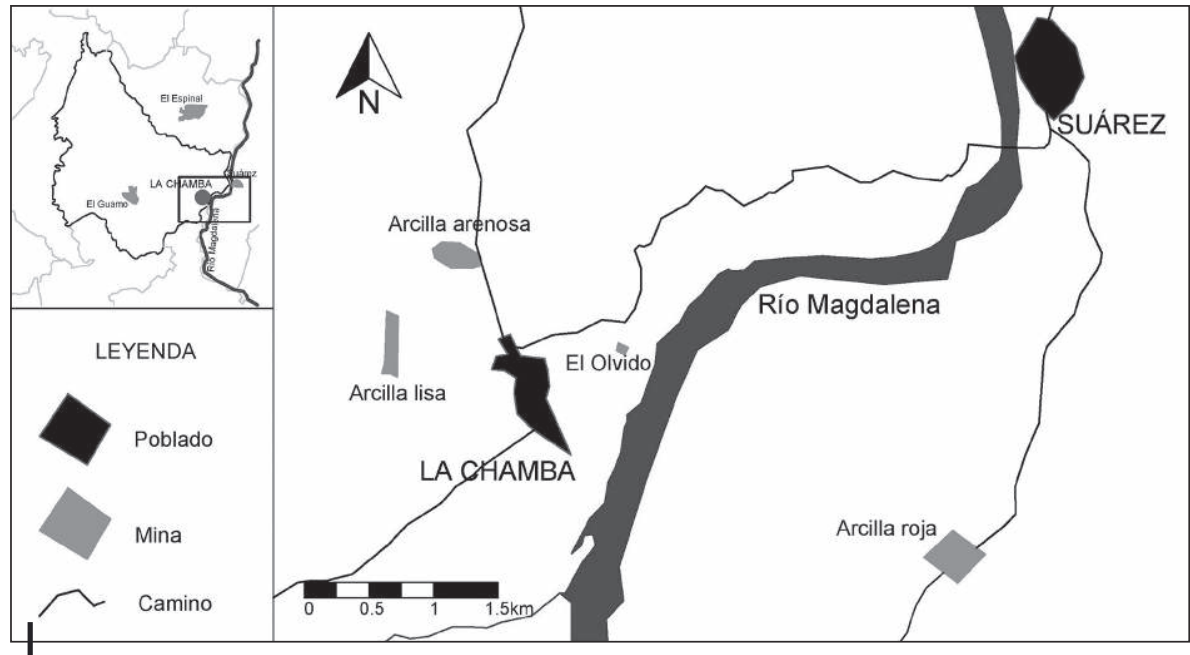

Figura 4 - Mapa de distribución de las minas

Fuente: Elaboración propia

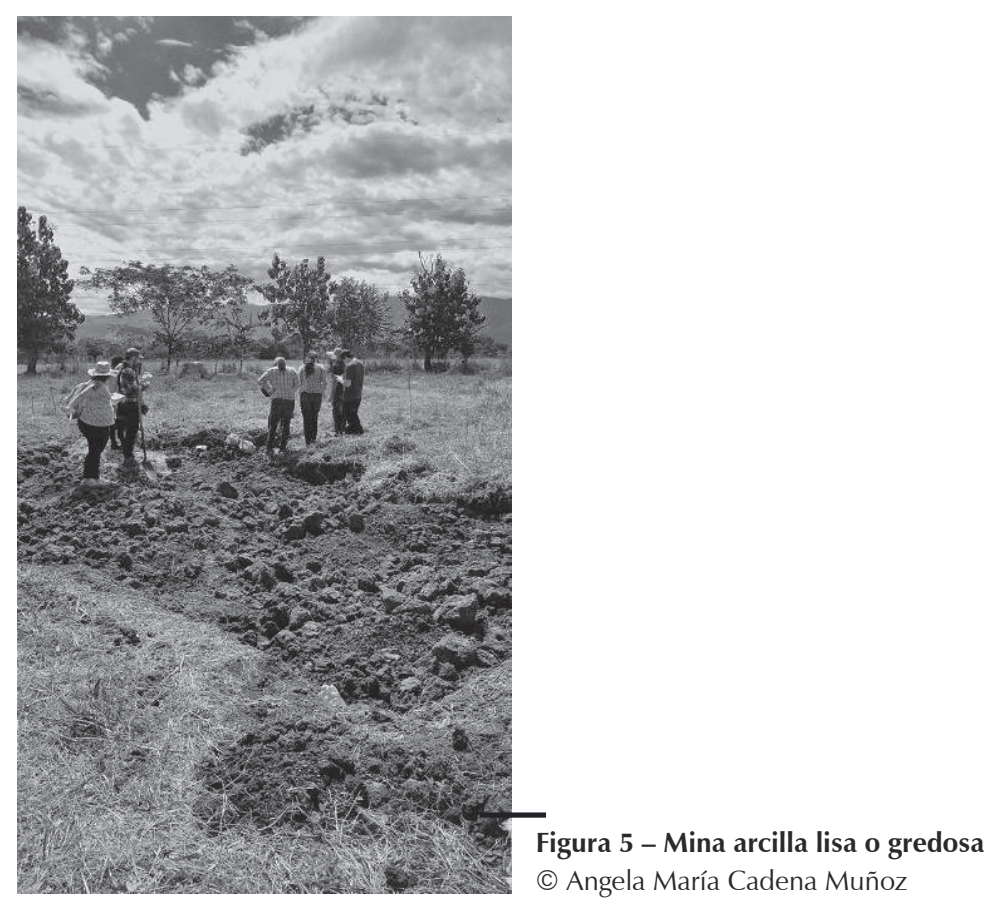




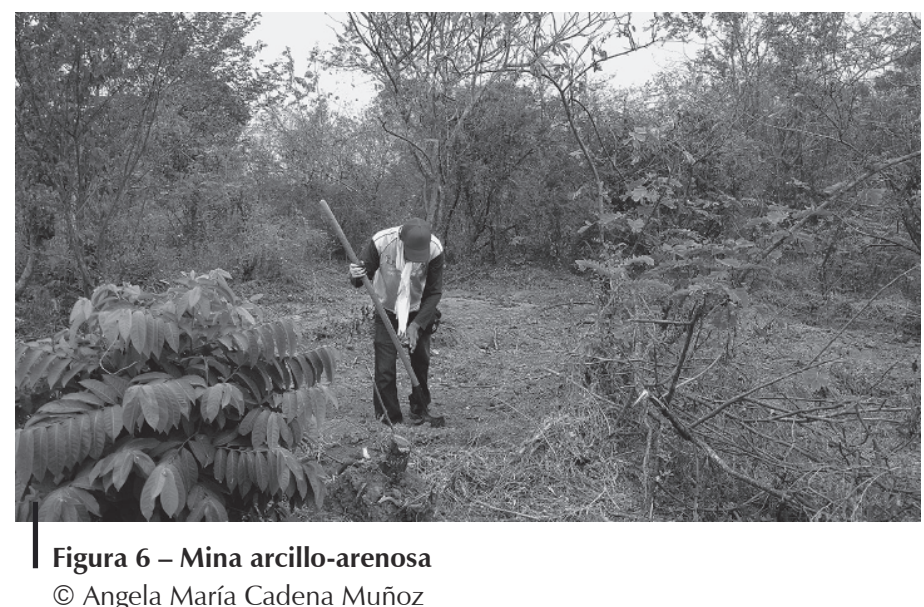

Los hombres son quienes realizan el proceso de extracción de los dos tipos de arcilla. Visitan las minas cuando el material escasea en el taller; normalmente, uno o dos hombres ejecutan esta acción a través del método de explotación de minas a cielo abierto, el cual consiste en excavar, con ayuda de picas y palas, un orificio de aproximadamente $60 \mathrm{~cm}$ de diámetro y de 60 o $70 \mathrm{~cm}$ de profundidad. Se dejan expuestos algunos de estos orificios para que otras personas tengan acceso a la arcilla. Sin embargo, los informantes expresan que las perforaciones no deben permanecer por mucho tiempo expuestas, puesto que el mineral debe regenerarse debajo de la tierra, lo que evidencia la preocupación compartida por la mayoría en torno al cuidado de la mina.

Una de las mayores precauciones de los hombres al escoger la arcilla, consiste en detectar que el suelo contenga la menor proporción de lo que se denomina «oropel», puesto que, según su conocimiento, este componente daña la producción de la cerámica en el momento de su cocción.

Geológicamente, se puede interpretar el oropel como micas laminares y brillantes denominadas «muscovitas», producto de las formaciones geológicas del lugar, pues se encuentran principalmente en rocas volcánicas como el granito o en rocas metamórficas como los esquistos (Varela Guarda, 2002: 228; Artesanías de Colombia S. A., 2003: 15). Por tal razón, es posible hallar diferentes perforaciones en la mina, en el momento de la búsqueda de la veta con condiciones idóneas para el modelado.

Después de su extracción, la arcilla se deposita en lonas o costales de yute (Corchorus olitorius) para ser transportada a los talleres por medio de motocicletas, bicicletas, burros o por los mismos artesanos (al hombro). En los talleres, que se encuentran normalmente en la parte posterior de las viviendas, las arcillas se extienden en lonas y son secadas al sol, por lo menos, por tres días. Posteriormente, son llevadas al molino mecánico. Allí, los artesanos pagan una suma de dinero para que cada tipo de arcilla sea triturado y convertido en polvo fino. 


\section{1. 2. La mina roja}

La arcilla roja es captada en el municipio vecino de Suárez (Tolima), precisamente en la vereda Batatas, a $14 \mathrm{~km}$ al nororiente de La Chamba (véase la fig. 4). El acceso a Suárez es por carretera, lo cual toma alrededor de veinte minutos en automóvil desde el casco urbano de La Chamba. Sin embargo, no siempre fue así. Antes de construir la vía al Espinal (alrededor de 1970), era necesario cruzar el río Magdalena en canoa. El recorrido por el río duraba diez minutos y era necesario caminar alrededor de una hora para llegar a la mina.

Al visitar la mina, fue posible observar ciertas condiciones geológicas del lugar: la vereda Batatas tiene suelos de origen fluvial, marino o lacustre, denominados «gleysoles». Estos se caracterizan por tener compuestos ferrosos en condiciones reductoras, lo que significa que cuando el nivel freático baja, se exponen las capas más superficiales y se precipitan los óxidos de hierro. Por ende, los colores son rojizos y las capas inmediatamente inferiores muestran condiciones reductoras por estar cubiertas de agua. La textura de este suelo es arcillosa, condición clara para su uso como engobe (J. Martínez, comunicación personal, 29 de noviembre de 2019).

Esta vereda ha sido, por muchos años, utilizada como sitio de captación de arcilla roja; sin embargo, las minas no siempre han sido las mismas. En la memoria colectiva de los pobladores de La Chamba, una de las minas antiguas estaba ubicada en la finca Bocayana, aproximadamente a $5 \mathrm{~km}$ de distancia del predio moderno. A pesar de recordar la utilización de esta mina, no se tiene claro el motivo de su desuso.

En la actualidad, la mina se encuentra en la finca Pitiguay, lugar en el que se ha explotado el mineral durante casi seis décadas. Hoy en día, el señor Luis Mejía, dueño del predio, lo vende por «latas», es decir, costal o lona que contiene alrededor de diez kilos de arcilla. El precio de estas depende de la manera como se obtenga la arcilla. Los artesanos pueden ir personalmente a captarla, siempre acompañados por el señor Luis, quien les indica el camino y el lugar en donde se encuentra la mina apta para la captación, y se cerciora, además, de su buen mantenimiento. Los hombres deben llevar sus herramientas y obtener la arcilla por su cuenta. Deben asegurarse que, al frotar el mineral con los dedos, este deje una marca de color intenso.

En la otra manera de obtener el mineral, el encargado del predio extrae el material, lo empaca en las lonas y, finalmente, vende las latas en su casa. Este modo es un poco más costoso. Los alfareros se ahorran el esfuerzo físico de ir a la mina y confían en el conocimiento del encargado.

La explotación de esta mina también es a cielo abierto, pero a diferencia de las otras dos, los orificios permanecen abiertos. Esto quiere decir que solo se explota una veta y cuando esta se agota, se busca otra, normalmente cerca de los antiguos orificios (véase la fig. 7). 


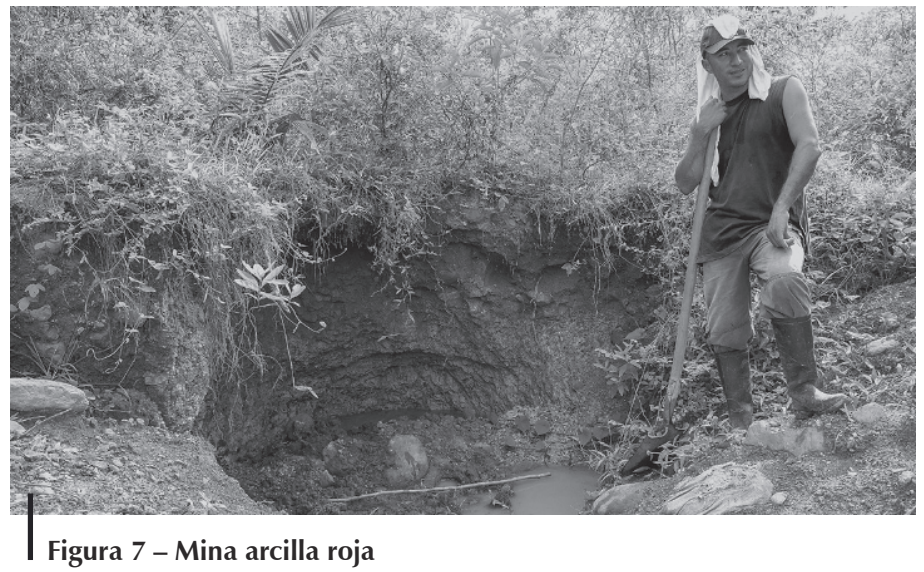

(C) Andrés Uribe Naranjo

\section{2. La pasta y el engobe}

La pasta es una mezcla de arcilla y desgrasante empleada en la confección de vasijas y objetos cerámicos (Heras y Martínez, 1992: 27). Las cualidades de la pasta dependen de las decisiones de los/as alfareros/as quienes conocen perfectamente los atributos de esta para trabajarla.

Para crear la combinación perfecta, los chambunos (gentilicio de los habitantes de La Chamba) comienzan por cernir cada una de las arcillas para eliminar residuos y remojarlas por separado.

La arcilla gredosa se sumerge en agua y se deja allí hasta que tome una consistencia espesa. Luego se tamiza con un cedazo fino o una tela, con el fin de que la arcilla quede completamente líquida y libre de impurezas. La arcilla arenosa también se humedece y se criba, pero solo con la intención de disgregar el suelo y dejarlo suave al tacto.

Después de que ambas arcillas se hallan acuosas, se mezclan, teniendo la arcilla arenosa como base (aproximadamente el $60 \%$ ) y agregando pequeñas porciones de arcilla gredosa (cerca del $40 \%$ ) hasta obtener una textura arenosa y ligeramente pegajosa. Si bien existe un aproximado en el porcentaje de las arcillas, esta decisión depende de las predilecciones de los/as alfareros/as.

Por otro lado, la arcilla roja, a la que se denomina «barniz» o «engobe» se sumerge en agua; cuando se tiene una solución coloidal, se pasa por un cedazo muy fino, normalmente una tela, hasta conformar una sustancia acuosa, pero espesa, que será aplicada a las piezas. Este revestimiento de material arcilloso se utiliza para taponar los poros, así como para impermeabilizar los objetos por medio del agregado de planos densos en las superficies, lo cual, además, facilita el desplazamiento del pulidor (véase la fig. 8). 


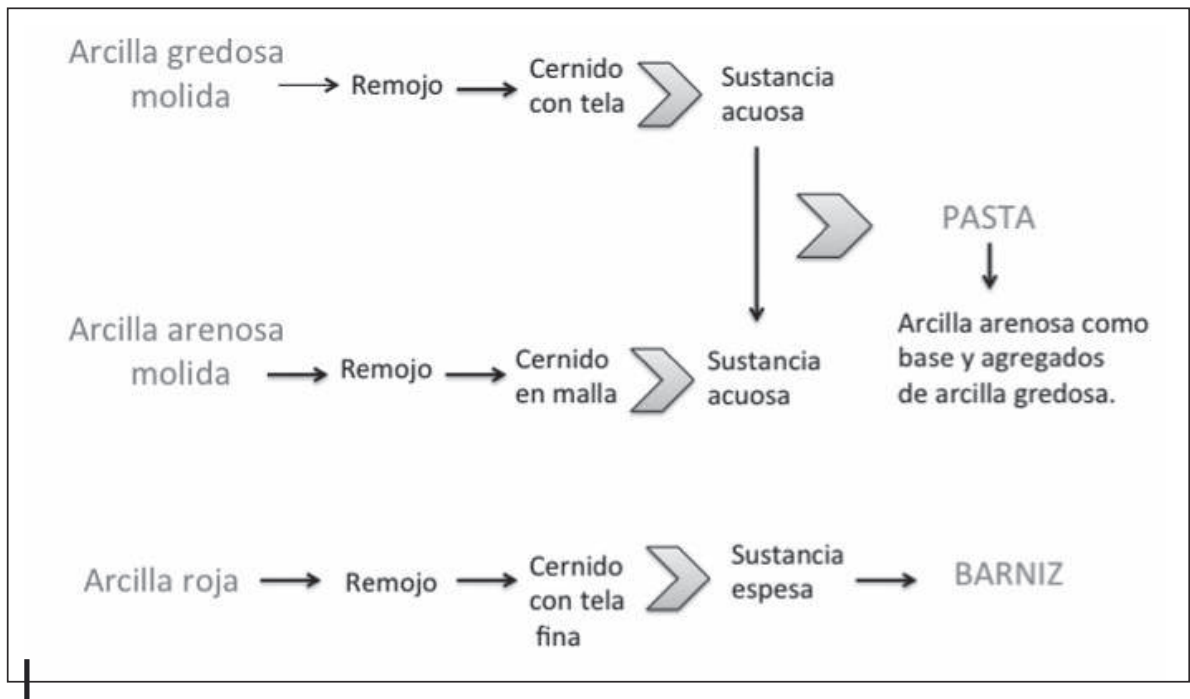

Figura 8 - Síntesis del procesamiento de las arcillas

Fuente: Elaboración propia

\section{DISCUSIÓN}

\section{1. El barro de La Chamba}

No existe un/a alfarero/a de La Chamba que desconozca de dónde proviene la arcilla, ya que la acción comunitaria de definir las minas y explotarlas se enmarca dentro de un amplio conocimiento y aprovechamiento del medio. Por lo tanto, existe una relación estrecha con este, puesto que al momento de escoger el lugar de extracción de las arcillas y comenzar a operar con la materia prima, esta recobra materialidad, emerge en la vida social, $y$, al entrar en contacto con los agentes, crea una conexión entre sus atributos y el conocimiento que se ve expresado en las manos de los artesanos. De tal forma que estos asumen la arcilla como un componente cultural, como eje central de la vida económica de los pobladores; la arcilla forma parte de la vida de los chambunos, ambos confluyen y estos se apropian de ella.

Así pues, los/as alfareros/as indican que «si no tuviéramos las minas no seríamos nada... el barro es todo, es nuestra vida, nos da todo», porque hasta el nombre del poblado lo asocian a la actividad alfarera, como lo da a entender el alfarero Idelfonso Avilés: «chamba significa hoyos o huecos que se excavan en el suelo, las chambas que se forman al extraer la materia prima para elaborar las piezas cerámicas, así como chamba significa trabajo, y eso es lo que nos caracteriza, porque hacer un plato requiere de mucho esfuerzo» (comunicación personal, abril de 2018). 


\section{2. El papel del aprendizaje}

¿Qué relación tiene exactamente la comunidad de alfareros de La Chamba con el «barro»? Para responder esta pregunta, es importante exponer el aprendizaje del oficio. Las mujeres, quienes en primacía manufacturan y bruñen las piezas, adquieren el conocimiento de generación en generación.

Por consiguiente, estas comparten sus saberes con niñas, niños y otras mujeres residentes de la comunidad, pero no nativas de ella. Estas últimas, interesadas en formarse como alfareras, aprenden las labores a través del conocimiento empírico, pues, en la mayoría de los casos, se instruyen viendo o imitando lo que las alfareras realizan, intentando reproducir de forma idéntica las acciones y gestualidades técnicas, esperando ser corregidas para perfeccionar su acción.

En el caso de los/as niños/as, la relación con la arcilla es natural; de manera cotidiana tienen contacto con la materia prima, pues en las casas/talleres, las arcillas, herramientas, moldes y pulidores son objetos corrientes con los que conviven. En este sentido, el conocimiento técnico se trasmite a través de un aprendizaje dentro del grupo familiar. Los/as niños/as tienen acceso al aprendizaje de igual manera, pero en su adolescencia y/o adultez, las mujeres asumirán el papel de alfareras, mientras que los hombres, por lo general, se dedicarán a otras labores económicas.

Otra actividad representativa en la enseñanza y el aprendizaje está relacionada con el reinado del barro. Cada dos años, a mediados de octubre, en el marco del festival del barro, se desarrolla este certamen que tiene como fin condecorar a la señorita que demuestre habilidades y conocimiento en las técnicas alfareras. Pero para participar, las jóvenes deben prepararse. Para esto, consultan a expertas alfareras que las «entrenan». Así, los saberes se transmiten de una manera rigurosa, pues las jóvenes deben perfeccionar las técnicas para afrontar los retos del evento.

En el reinado, las candidatas hacen caravanas por la calle principal de La Chamba, lucen vestidos típicos y objetos representativos de la región; los familiares y amigos acompañan y animan con clamor a las señoritas. La intención es darse a conocer entre el público (así ya sean conocidas) y ganar adeptos. La última noche del festival, se realiza el evento de elección y coronación de la señorita del barro. En un espacio abierto o en la cancha de fútbol arman una tarima en donde ocurren los hechos. El jurado, normalmente compuesto por una maestra alfarera, una exreina del barro y un invitado especial (un maestro alfarero, una figura política, un profesor, etc.), está ubicado en un lugar estratégico de la tarima con el fin de tener buena visibilidad. Su objetivo es calificar en las participantes tres aspectos: el conocimiento general de la región, un baile típico (bambuco) y la elaboración de una pieza de barro.

Aunque todas las actividades son importantes, la que más tensión causa en el público y en las candidatas es la última prueba, puesto que tienen diez minutos para manufacturar la pieza de su elección; ellas llevan la arcilla preparada y la base de la pieza lista para empezar a modelar. Normalmente, realizan pocillos 
o platos que son los objetos de fácil elaboración. Pasados los diez minutos, los miembros del jurado examinan el resultado y se toman un tiempo para debatir entre ellos los puntajes de las candidatas y, finalmente, indicar la ganadora.

Ser reina del barro es un gran prestigio, no solo para la participante, sino también para su familia, puesto que la señorita ganadora será la imagen de La Chamba en distintos eventos municipales y, como tal, deberá demostrar su conocimiento alfarero, representar a la comunidad y a su familia.

De manera que el proceso de enseñanza y aprendizaje es concebido en un nivel social, es decir, «lo que se trasmite no es únicamente el saber hacer del maestro, sino que engloba el conocimiento tecnológico que tiene el grupo. Por lo tanto, no se trasmite un conocimiento tecnológico individual, sino el conocimiento tecnológico social e identitario» (García Roselló, 2011: 70).

\section{3. La elección de los materiales}

En consecuencia, al entrar en contacto con el agua y las manos de las alfareras, la arcilla se desliza con facilidad entre los dedos y recobra significado y conocimiento (véase la fig. 9). Así, de manera habilidosa, trabajan en conjunto arcilla y artesana, y se levantan piezas a través de técnicas como el pellizcado o enrollado y modelado. En este sentido, el barro emerge en la sociedad y junto con ella, configura redes sociales, económicas y políticas que constituyen al pueblo; la arcilla se comporta como un índice del cual se genera agencia, con cualidades significantes dentro del grupo que se reflejan en saberes, dedicación y especialización de las técnicas. En virtud de ello, Carmen Prada, alfarera de la zona, hace alusión a la arcilla de esta manera: «el barro de aquí es el mejor, porque la arcilla sale en todos lados, pero el barro... el barro sale en La Chamba» (comunicación personal, abril de 2018). En estas palabras se encuentra inmerso el mundo de los/as alfareros/as de esta región.

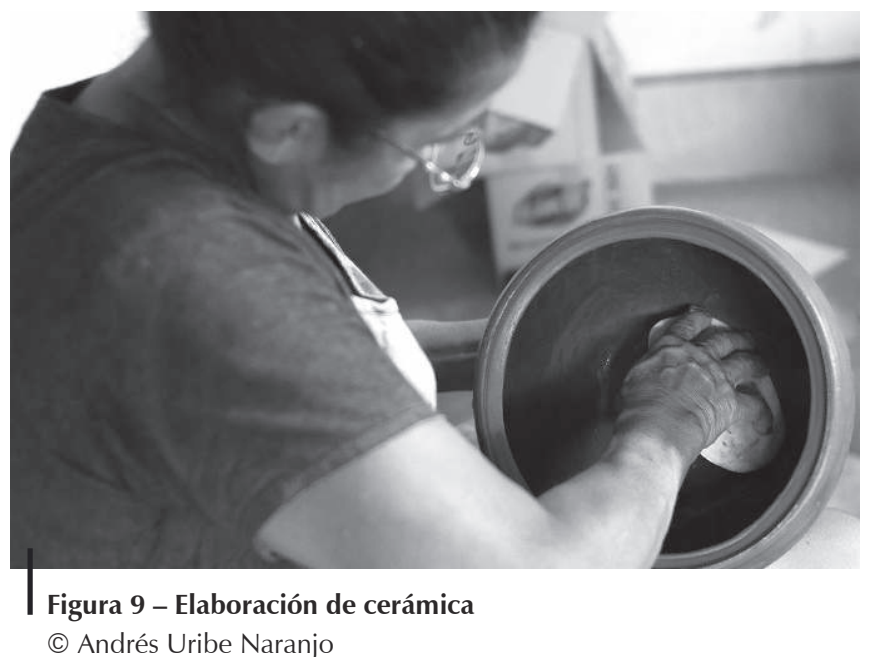


Si bien los agentes son conscientes de que existe un universo de opciones para realizar una misma actividad, a través de su conocimiento, ellos son quienes seleccionan las acciones tecnológicas pertinentes relacionadas con su saber hacer, por lo cual asumen como opción idónea la materia prima de La Chamba, aquella que al deslizarse suavemente por los dedos evidencia una textura arenosa fina.

En cuanto a la arcilla roja o barniz, la mina del municipio de Suárez es considerada como el único lugar de extracción del material, puesto que el conocimiento tradicional y el saber hacer de los/as alfareros/as ha determinado que las características de la arcilla de este municipio son las apropiadas para el engobe. En el sector El Olvido (de la vereda La Chamba), se halla un horizonte de suelo con características similares a la de la mina de barniz, pero los/as artesanos/as no hacen uso de este, ya que su consistencia es menos espesa, y, al momento de aplicarla a la superficie, genera capas delgadas, por lo cual su uso requiere más trabajo y material.

En general, los/as alfareros/as tienen claridad sobre las características del engobe, esas que deben tenerse en cuenta desde el momento de su hallazgo, pasando por su preparación y, finalmente, el uso como engobe. La mina en Suárez conjuga todas las propiedades que ellas y ellos buscan para la manufactura cerámica, por lo tanto, esta (la mina) se ha convertido en el sitio «social» de captación de la materia prima.

\section{CONCLUSIÓN}

Los estudios etnoarqueológicos no siempre deben estar relacionados con modelos para la aplicación arqueológica directa, sino como una manera de pensar diferentemente los compromisos de las personas con el material y para probar y desarrollar la teoría arqueológica en tiempo real (Lyons \& Casey, 2016: 612). Por tal razón, al analizar los componentes que caracterizan actualmente la tradición cerámica de La Chamba, es posible proponer modos de interpretación para identificar la variabilidad de decisiones sociales involucradas en el proceso alfarero. La relación que tiene la comunidad con la arcilla es precisamente un componente de especial interés en el momento de analizar la producción cerámica, la cual no se halla necesariamente asociada con el principio de menor esfuerzo. Por el contrario, se identifican elecciones realizadas por alfareros/as, tanto espacial como tecnológicamente, para seleccionar los materiales. En el caso particular, se ilustra la complejidad de los aspectos involucrados en la selección de la materia prima con la determinación de usar el engobe rojo de una mina específica sin importar la distancia y el costo.

En consecuencia, el análisis de las estrategias productivas en el presente es ideal para llegar a un buen estudio de los procesos de fabricación cerámica, puesto que «las prácticas materiales de las sociedades constituyen un medio a través del cual se mantienen y refuerzan los comportamientos culturales, pero al mismo tiempo ofrecen la estructura a partir de la cual operan los cambios o transformaciones» (De la Fuente \& Páez, 2007: 2). 
Claro está que no se busca crear una metodología específica para el análisis de la cerámica arqueológica, puesto que las conclusiones etnográficas son complejas de llevar directamente a la arqueología. Sin embargo, es importante tener en cuenta todo el contexto en el que ocurren las elecciones y así comprender las diferentes posiciones en torno a las decisiones humanas, abriendo las puertas de análisis que permitan pensar desde otras perspectivas los materiales, los lugares y los contextos (Gosselain \& Livingstone Smith, 2005: 34). Por lo tanto, este estudio evidencia correlatos materiales posibles de dichas elecciones y aporta ejemplos adicionales al estudio de la tecnología cerámica en términos de prácticas sociales de producción, aspectos fundamentales para el análisis de la cultura material que, en la mayoría de casos, no son tomados en cuenta por los estudios arqueológicos, mayormente fundamentados en producciones tipológicas y descriptivas.

\section{Referencias citadas}

ARTESANÍAS DE COLOMBIA S. A., 2003 - Proyecto para el Mejoramiento de la Competitividad del Sector Artesanal Colombiano. Convenio FIDUIFI - Artesanías de Colombia S. A. Fomipyme. Plan de manejo ambiental minas de arcilla Vereda de la Chamba-Tolima. Bogotá, Colombia. 60 pp.

CALVO TRÍAS, M. \& GARCÍA ROSSELLÓ, J., 2014 - Acción técnica, interacción social y práctica cotidiana: propuesta interpretativa de la tecnología. Trabajos de Prehistoria, 71 (1): 7-22.

CASTELLANOS, D., 2007 - Huellas de la gente del cerro: detalles etnográficos sobre estilo, ritos de paso y envidia en la formación de un contexto arqueológico, 134 pp.; Bogotá: Universidad de los Andes, Departamento de Antropología. Tesis de maestría.

CASTELLANOS, D., 2012 - Alfareros de Aguabuena: notas etnográficas de (sus) fragmentos. Maguaré, 26 (2): 239-254.

CASTELLANOS, D., 2019 - Vasijas envidiosas de Aguabuena: un ensayo etnográfico sobre la vida del mundo material. In: Cosas vivas. Antropología de objetos, sustancias y potencias (L. A. Suárez Guava, ed.): 51-70; Bogotá: Editorial Pontificia Universidad Javeriana.

CIFUENTES TORO, A., 1994 - Tradición alfarera de La Chamba. Boletín de Arqueología, 9 (3): 3-78.

CIFUENTES TORO, A., 1996 - Arqueología del municipio de Suárez (Tolima). Boletín de Arqueología, 11 (1): 35-60.

CORPORACIÓN AUTÓNOMA REGIONAL DEL TOLIMA (CORTOLIMA), 2009 - Agenda Ambiental del Municipio de Guamo. Documento Técnico, 109 pp.; Ibagué.

DE LA FUENTE, G. A. \& PÁEZ, M. C., 2007 - Introducción. In: La Cerámica Arqueológica en la Materialización de la Sociedad. Transformaciones, Metáforas y Reproducción Social (M. C. Páez \& G. A. De La Fuente, eds.): 1-8; Oxford: Archaeopress. 
Saber hacer y tradición en La Chamba, Colombia: un estudio etnográfico de la selección de arcillas

DRUC, I., 2009 - Tradiciones alfareras, identidad social y el concepto de etnias tardías en Conchucos, Ancash, Perú. Bulletin de I'Institut Français d'Études Andines, 38 (1): 87106. doi: 10.4000/bifea.2853

GARCÍA ROSELLÓ, J., 2008 - Etnoarqueología de la producción cerámica. Identidad y territorio en los valles centrales de Chile. Mayurka, 32: 1-328. Número monográfico.

GARCÍA ROSELLÓ, J., 2011- Modelado, aprendizaje y espacio social: una reflexión desde la tecnología cerámica. Revista Werkén, 14 (1): 69-80.

GONZÁLEZ-RUIBAL, A., 2017 - Etnoarqueología, arqueología etnográfica y cultura material. Complutum, 28 (2): 267-283.

GOSSELAIN, O. P., 2016 - To hell with ethnoarchaeology! Archaeological Dialogues, 23 (2): 215- 228.

GOSSELAIN, O. P. \& LIVINGSTONE SMITH, A., 2005 - The source: Clay selection and processing practices in Sub-Saharan Africa. In: Pottery Manufacturing Processes: Reconstitution and Interpretation (A. Livingstone Smith, D. Bosquet \& R. Martineau, eds.): 33-47; Oxford: Archaeopress.

GUBER, R., 2011 - La Etnografía. Método, campo y reflexividad, 160 pp.; Buenos Aires: Siglo Veintiuno Editores, Artes gráficas del Sur.

HERAS Y MARTÍNEZ, C. M., 1992 - Glosario terminológico para el estudio de las cerámicas arqueológicas. Revista Española de Antropología Americana, 22: 9-34.

LEMONNIER, P., 1992 - Elements for an Anthropology of Technology, xii + 129 pp.; Ann Arbor: University of Michigan, Museum of Anthropology.

LYONS, D. \& CASEY, J., 2016 - It's a material world: the critical and on-going value of ethnoarchaeology in understanding variation, change and materiality. World Archaeology, 48 (5): 609-627. doi: 10.1080/00438243.2016.1214619

MINISTERIO DE CULTURA, 2014 - La Chamba, donde el río pasa entre loza negra y roja, 48 pp.; Bogotá: Ministerio de Cultura, Fundación Tridha, Corporación integradora de los artesanos de la cerámica roja y negra de la vereda La Chamba (Corartechamba).

MONTERO FAYAD, V., 2002 - Tradición disidente: aporte para una reflexión crítica sobre las artesanías, 145 pp.; Bogotá: Universidad de los Andes, Departamento de Antropología. Monografía de grado.

POLITIS, G. G., 2002 - Acerca de la Etnoarqueología en América del Sur. Horizontes Antropológicos, 8 (18): 61-91.

POLITIS, G. G., 2014 - Ethnoarchaeology. In: Encyclopedia of Global Archaeology (C. Smith, ed.): 2523-2530; Nueva York: Springer.

POLITIS, G. G., 2015 - Ethnoarchaeology: Approaches to Fieldwork. In: Encyclopedia of Global Archaeology (M. Carver, B. Gaydarska \& S. Monton-Subias, eds.): 25302535; Nueva York: Springer.

PULIDO GONZÁLEZ, O., 2019 - Arcillas. In: Recursos minerales de Colombia, vol. 1: 4793; Bogotá: Servicio Geológico Colombiano.

RAMÓN JOFFRÉ, G., 2011- The swallow potters: seasonally migratory styles in the andes. In: Archaeological Ceramics: A Review of Current Research (S. Scarcella, ed.): 160175; Oxford: Archaeopress.

SALGADO LÓPEZ, H., LLANOS CHAPARRO, J. M. \& GÓMEZ GARCíA, A. N., 2007 Una secuencia cultural prehispánica en la planicie cálida del valle del Magdalena tolimense (Colombia). Boletín de Antropología Universidad de Antioquia, 21 (38): 253-274. 
VARELA GUARDA, V., 2002 - Enseñanzas de alfareros Toconceños: tradición y tecnología en la cerámica. Chungara. Revista de Antropología Chilena, 34 (2): 225-252. doi: 10.4067/S0717-73562002000200006

VIDAL, A. \& GARCíA ROSELLÓ, J., 2010 - "Dime cómo lo haces": una visión etnoarqueológica de las estrategias de aprendizaje de alfarería tradicional. Arqueoweb. Revista sobre arqueología en internet, 12 (1). 